\title{
MATERNAL EMPLOYMENT, CHILD CARE, AND NUTRITIONAL STATUS OF 12-18-MONTH-OLD CHILDREN IN MANAGUA, NICARAGUA
}

\author{
JESSICA F. LAMONTAGNE, ' PATRICE L. ENGLE ${ }^{2 *}$ and MARIAN F. ZEITLIN ${ }^{3}$ \\ 'Program in International Nutrition, University of California, Davis, CA, U.S.A., 'Department of \\ Psychology, Cal Poly State University, San Luis Obispo, CA 94307, U.S.A. and ${ }^{3}$ School of Nutrition, \\ Tufts University, Boston, MA, U.S.A.
}

\begin{abstract}
Relationships among women's employment, child care strategies, and nutritional status of children 12-18 months of age were examined in 80 Nicaraguan households sampled by randomized block design in 10 low income urban communities. Multiple regression analyses showed that children of employed mothers $(56 \%)$ fared better in weight/height than those whose mothers were not employed, with and without controlling for socioeconomic status and maternal education, paternal financial support, child care adequacy, and sex and age of the child. Children with inadequate alternate child care (care by a preteen or care at the work place) had lower height for age, even controlling for the same variables and for maternal employment. Differences in 10 caregiving behaviors between families as a function of work status of the mother and adequacy of child care were examined. In families with working mothers, caregivers were less likely to be observed washing their hands, suggesting that the positive associations of work for earnings might be due to income rather than improved care. Inadequate care was associated with less food variety, less use of health care, and marginally less handwashing. Inadequate child care, which tends to be associated with informal work, nuclear families and poverty. should be a concern for child welfare.
\end{abstract}

Key words-child care, child nutrition, maternal employment, Nicaragua

\section{INTRODUCTION}

Women's participation in the work force in developing countries has been increasing steadily over the last several decades, particularly in Latin America (United Nations, 1995). The rate increased by three percentage points in the 1970 s, and by nine percentage points, to $34 \%$, in the 1980 s. Nicaraguan women's official labor force participation has increased from $23 \%$ of women in 1980 to $30 \%$ in 1994 (United Nations, 1995). The actual proportion of women working is likely to be much higher given that women are disproportionately represented in the informal sector of most economies, a sector seldom accounted for in labor statistics (United Nations, 1990). Data from some Latin American cities suggests that as many as $50 \%$ of women are working for earnings (United Nations, 1990). The effects of maternal employment on child welfare are of enormous importance to development policy as healthy child development and improved economic opportunity for women are two general goals of development agencies worldwide.

An extensive review by Leslie (Leslie and Paolisso, 1989; Leslie, 1988) shows some positive and some negative relationships between women's work for earnings and the nutritional status of their children. Many of the earlier studies reviewed did not control for confounding variables. A few recent studies which have controlled for confounders have shown a positive effect of maternal income on children's nutritional well being, particularly among children aged one to two (Adelman, 1983; Engle and Pedersen, 1989; Vial and Muchnik, 1989). However, the conditions under which effects are positive or negative are not always clear. We do not yet have a mechanism for explaining the findings.

Economists have proposed that there is a tradeoff between the benefits for children of mothers' increased income and the costs of reduced time of the mother in child care. However, this model contains many untested assumptions. One problem with the income side of the equation is that we have evidence that not only the amount of income, but also who controls the income may have different effects on food availability and distribution for children (Blumberg, 1988; Engle, 1993; Engle and Nieves, 1993). A second problem in many studies is the failure to control for differences between working and non-working women, such as marital status, education, and poverty, which may also influence children's nutritional status (Leslie and Paolisso, 1989; Engle, 1991).

A third problem with the model is that we know little about how variations in maternal time and caregiving behaviors affect children, and what the 
significance of alternative child care arrangements might be for children in Latin America. In the U.S., an extensive body of research suggests that if adequate alternative child care is available, there are no negative impacts of a mother's employment on the child (Hoffman, 1989). In the much more economically and environmentally stressed situations in which many working Latin American women live, this conclusion may not hold. We need to know what constitutes "adequate child care" in these situations, and to examine changes in the caregiving behaviors of working mothers as a function of work. This study was designed to compare the caregiving behaviors observed among working and nonworking mothers with children aged 12-18 months in Latin American barrios.

Maternal employment usually results in a loss of child care time; presumably the mother is therefore less available for breastfeeding, making frequent meals, etc. However, it is possible that non-working mothers also spend relatively little time in child care, or that important caregiving behaviors continue to be performed if there is adequate substitute care. There are few studies which compare these child care behaviors of working and non-working mothers explicitly. Tucker (1989) found maternal care time to decrease significantly when mothers worked away from home. When the time of substitute caregivers was included in the total care time, no significant difference in total child care time remained.

The role of the primary care provider in child welfare may not have been extensively studied because caregiving can be difficult to define and observe, and to interpret across cultures (Engle et al., 1997). Child care refers both to actual caregiving behaviors such as feeding and cleaning a child, and to the beliefs, customs, and cultural norms governing the execution of these behaviors (Engle, 1992). Care can also refer to the support that the family or community provides to the primary caregiver, which along with caring behaviors make up the developmental niche (Super and Harkness, 1986) or the care/support niche (Engle, 1992). Since the primary care providers in all cultures are women (Barry and Paxson, 1971) care of the child is inextricably linked with the situation of the household and the situation of women.

The framework of a "care/support niche" proposed by Engle (1992) can be used to define adequate child care. In this model, three factors need to be considered in evaluating the child care situation: where the care takes place, who the caregiver is, and who is supporting the family (and what, therefore, are the demands on the mother's time). Care could take place in the home, at the work place, at the home of another caregiver, or at an institutional site. The caregiver could be the mother, an adult female or male, or a young sibling. Support could be provided by the father only, mother and father, mother only, or extended family. The model needs to be adapted to each setting, and the most common patterns identified. Each can then be examined to ascertain its adequacy. For example, based on analyses of the work place, we judged caregiving in the work place to be more problematic than at the home, and care by a young child to be less adequate than by an older woman. Researchers have found that children had better nutritional status if they were cared for by an adult caregiver (Engle, 1991; Shah et al., 1979).

In our Nicaraguan sample, it was possible to examine caregiving behaviors, and the effects of the care/support niche on young children since more than half of the mothers of the young children worked for cash income. Subjects were between 12 and 18 months of age, a period during which maternal work for earnings has been associated with positive effects for children (Engle and Pedersen, 1989; Vial and Muchnik, 1989). We could examine a few of the possible mechanisms to explain either positive or negative effects of maternal employment through examining adequacy of the mother's alternate child care arrangements, and her caregiving behaviors during the time that she was with the child.

If positive effects of maternal work for earnings were found for child nutritional status, the explanation could either be that the increased income was used more directly for child feeding, or that the working mothers had better systems of child care or caregiving behaviors than non-workers. This paper examines the associations among maternal employment status, caring behaviors, the care/support niche, and the child's nutritional status. Our hypotheses were (1) there will be a positive association of maternal employment with child welfare in this age group, i.e. the benefits of maternal employment would outweigh the costs, when controlling for wealth and mother's education; (2) there will also be positive effects of the care/support niche (paternal and extended familial support and the quality of substitute child care) on children's nutritional status; and (3) when they are at home, the caregiving behaviors of women who work and those who do not will not differ.

\section{METHODS}

\section{Research setting}

The sample consisted of 80 households with children aged 12-18 months, randomly selected from 10 low income neighborhoods around Managua (Table 1). Low income was determined by geographical risk classifications obtained from the Ministry of Health (MINSA) and confirmed by visual inspection of the neighborhoods. Streets in the neighborhoods were generally unpaved. Houses were commonly constructed of cement blocks or 
Table 1. Description of the sample

\begin{tabular}{lcc}
\hline & Mean (SD) & \\
Age of child (months) & $15.4(1.86)$ & \\
Height for age $z$-score (HA) & $-1.50(1.06)$ & \\
Weight for age z-score (WA) & $-1.32(0.98)$ & \\
Weight for height $z$-score (WH) & $-0.50(1.06)$ & \\
Years of maternal education & $5.4(3.4)$ & \\
& Frequency & Percent \\
Children <-2.0 SD HA & 22 & 27.5 \\
Children <-2.0 SD WA & 17 & 21.3 \\
Children <-2.0 SD WH & 5 & 6.3 \\
& Head of household: & \\
Father & 39 & 48.8 \\
Mother & 8 & 10.0 \\
Parent of father or mother: & 21 & 26.3 \\
Other family relation Civil status of mother: & 15.1 \\
& 12 & \\
Single & 18 & 15.0 \\
Married & 41 & 22.5 \\
Consensual & 8 & 51.3 \\
Separated/divorced & 1 & 10.0 \\
Widowed & 21 & 1.3 \\
& Amount of financial support father provides: \\
Nothing & 21 & 26.3 \\
Partial & 43 & 17.5 \\
Everything & 2 & 53.8 \\
Father in the military & & 2.5 \\
\hline
\end{tabular}

wood, with some pieced together from scrap materials. The median house $(42 \%)$ had only one room. More than half of the houses had dirt floors; most had latrines as opposed to flush toilets, with no piped water nor drainage system.

More than half $(60 \%)$ of the families lived in extended family households. The average household size was 7.7 people, with an average of 2.2 children under 5 years of age. The majority of mothers $(51 \%)$ were not legally married but acompañada (in a consensual arrangement). Another $23 \%$ were legally married, $15 \%$ were single, and $12 \%$ were divorced, separated or widowed. One-quarter $(26 \%)$ of the children received no financial support from their fathers, according to the mother.

Mothers had an average of 5.4 years of education. Only $18 \%$ of the women had no formal education. Seventy percent had six years or less. Another 20\% finished between seven and 11 (last year of secondary school) years, and three women had some university or technical education.

The population of children was moderately undernourished with a mean height for age $z$-score (HA) from NCHS reference data of -1.50 . The mean weight for age $z$-score (WA) was -1.32 and weight for height (HA) was -0.50 . Over one quarter of the children $(27.5 \%)$ were below $-2.0 \mathrm{HA} z$ score and $6 \%$ were less than $-2.0 \mathrm{WH} z$-score, indicating that stunting is a more common problem than wasting in this population.

Nearly all the children had been breastfed, but very few were breastfed exclusively, with $58 \%$ started on a bottle at less than one month of age. Less than half the mothers $(48 \%)$ reported they were still breastfeeding and $66 \%$ of the children were bottlefed at the time of the interview. Half $(51 \%)$ of the children had been started on solid foods by three months of age, with $86 \%$ eating solid foods by six months. Diets of the children included rice and beans, with rice the most frequently observed food item. Vegetables were seldom served separately or in large amounts, but were added to rice and beans, or served in soup. Meats, if served, were given in small amounts added to the soup or rice dish. Tortillas were more common than bread. Fresca, a fresh fruit drink with added sugar and water, was served as often as cow's milk in the children's bottles.

\section{Sample}

Data were collected between the months of July and October in 1989. Random sampling was insured by selecting every fourth house for an attempted interview. If there was no child aged 1218 months, the house on the right, then the house on the left were sampled until a child of the appropriate age was located. Families were contacted in the morning for their willingness to participate in the study. If the adult family member present agreed, the observer immediately entered the home, and interviewed the caregiver. Approximately five families refused to be included in the study (refusals were not tracked carefully in the first few weeks of the study).

\section{Data collection and procedures}

Two days of observations were collected. On the first day, following the interview, the observer remained quietly observing in the home for an average of 3 hours, or until after the lunch meal. Observation of feeding behaviors was done by event sampling. An hour of behavioral observations were made in which child activity, caregiver activity, interaction, and other information were recorded every five minutes using time sampling techniques. A second observation of feeding events and behaviors were made approximately a week later, at the same time of day as the first. In order to be sure that the behaviors observed were again unplanned, the family was not given a specific time or date for the second interview.

Weights were taken to the nearest $0.1 \mathrm{~kg}$ using a hanging scale with a capacity of $25 \mathrm{~kg}$. for all children under four in the household. A wooden length measure built by the project was used to measure length. The interviewers were all members of the Faculty of Medicine, National Autonomous University of Nicaragua. A Tufts University Master's-level nutritionist trained and standardized the interviewers to take anthropometric measures according to methods recommended by WHO (Lavoipierre et al., 1983).

Two kinds of observational measures were used. For 2 hours on each visit, the behavior of the child and of the primary caregiver was coded every five minutes using a point time sampling technique. At exactly 5 minutes after the prior observation, the 
activities of the child and the principal caregiver were noted and recorded. The caregiver was defined as the most responsible person present, even if the child were interacting with someone else, such as a sibling. The child's activity was coded as one of 18 possible activities, such as playing, eating, or being held, and the caregiver's activity was coded as one of 19 possible activities such as holding the child or sweeping the floor. Over the 4 hours of observation on two separate days, 48 observations were made per child. Only the ratings of the caregiver's behavior were used here. The observers were trained to $85 \%$ reliability.

The second method of observation was an event sampling, in which the behaviors specific to an event, but not frequency or duration, are recorded. A total of 37 separate behaviors were coded for each eating event. This methodology has been described in detail elsewhere (Engle and Zeitlin, 1996). Acceptable interobserver reliability was obtained during the training process.

Food quality was assessed through observation of the foods ingested by the child during the midday meal, and by the mother's report of what kinds of food the child ate at breakfast and the evening before.

\section{Definition of variables}

Outcome measures. The Center for Disease Control Anthropometric Software Program was used to transform raw anthropometric measures into zscores of the NCHS/WHO reference data. Measures created were height for age z-score $(H A)$, which normally measures long-term undernutrition, weight for height z-score $(\mathrm{WH})$, which can reflect wasting, or acute undernutrition, and weight for age z-score (WA), which tends to assess both chronic and acute undernutrition (Martorell, 1989).

Child care/support niche. Maternal employment was defined as the mother's report of whether or not she worked for earnings in the past week. A woman was considered to be a "worker" if she had reported earning income at least once during the past week. For some analyses, work was recoded into formal and informal categories, with formal referring to regular wage work, such as secretary or clerk, and informal referring to street vending, domestic work, or vending from a fixed location.

The child care adequacy variable was based on the type of arrangements mothers reported using when they worked. The four categories reported were taking the child with them while they worked, working at home while watching the child, leaving the child with an adult caregiver, or leaving the child with a young (under 13) caregiver.

Unfortunately, income data were not collected in this study, due in part to the rapid rates of inflation during this period. Therefore, the only support measures available are the mother's report of the amount of support she received from the child's father (none, partial, or complete) and whether or not she lived with an extended family. Living with an extended family might mean that she was receiving financial support or additional child care.

Measures of caregiving behavior. Four kinds of caregiving behavior were examined, resulting in 10 separate behaviors: personal hygiene (two variables), percent of emotional and physical caregiving (two variables), food and feeding (five variables), and use of health services (one). Extensive description and analysis of these caregiving measures are reported elsewhere (Engle et al., 1992). All of the variables described here were based on observations, rather than reported data.

The hygiene variables were whether the caregiver was ever observed washing her hands before or during a feeding event, and whether the child's hands were ever washed during the two days (a total of about 8 hours of observation). Because handwashing usually occurred at the outside sink, it would have been easily visible to the observer.

Emotional care and physical care by the caregiver were calculated using the 48 time samples of the behavior observation. The 19 observed caregiver behaviors were categorized as providing emotional care, providing physical care, or neither. Behaviors reflecting emotional care were interacting with the child (talking, looking, teaching or gesturing) and holding or cuddling the child. Physical care included breastfeeding, feeding, dressing, bathing, or dressing the child. Activities coded as "neither" included laundering, washing dishes, personal care, watching TV, or chatting with others. Although many of these household production activities probably benefit children (e.g. washing dishes), the purpose of the observation was to note direct caregiving activities. The variables constructed were the percent of the 48 observations in which either emotional care or physical care activities were observed.

Among the five food and feeding variables were two measures of food quality, animal protein and food variety, two measures of feeding behaviors, the number of times child was observed to be fed and active feeding by caregiver, a variable described in detail elsewhere (Engle and Zeitlin, 1996), and whether or not the mother was still breastfeeding. These variables were observed during the two days in the house. Animal protein was the number of times the child was observed to receive an animal protein (meat, cheese, eggs, milk, and fish), and food variety was the total number of different foods the child was observed to be given.

The only health care variable in the study, completeness of vaccinations, was observed from the health post cards which were given to the mother when the child was brought in for vaccinations. Vaccinations are required for measles, polio, and DPT (diphtheria, tetanus and whooping cough), and screening for tuberculosis. The variable used 
here was completion of measles vaccinations, since all children should have been complete. Four of the mothers did not have vaccination cards for their children.

Socioeconomic status variables. Household wealth was used as a proxy for socioeconomic status. A score based on multiple indicators is better able to capture complexity and best represent the concept than a single indicator. For household wealth, a cluster of structural indicators of house quality and a list of household possessions were used to construct a scale. The house quality scale was constructed by giving points for quality of house construction (highest points for cement or brick, no points for shacks constructed of scrap materials; a point for an intact roof, no points for a roof constructed of scrap materials; no points for a dirt floor, one for a mixed floor, two points for a tiled or cement floor; no points for absence of windows, higher points for glass or wood shutters; one point for electricity; a point for each room with permanent separation. The possession scale gave a point for each of the household items on a pretested list. A test of reliability showed an alpha score of 0.85 .

Father's occupation had considerable missing data, and was not related to family wealth or to the child's nutritional status. Therefore, it was not used as a control variable. Literacy of either parent was not significantly related to nutritional status as there was almost no variability in this measure.

*For the Stress Scale the mother was asked to report how many times during the past week she had experienced a particular symptom. A total of 13 symptoms were presented to her. These included items such as headaches, lack of appetite, feeling of depression, crying, etc.

tThe mother was read a list of birth control methods and asked if she had heard of, or ever used a series of birth control methods. The number of birth control methods she knew, but not experienced, is positively correlated with her years of education, $r=0.44$ $P=0.000$. Some terms used in the questionnaire for birth control methods few mothers recognized although their practice may be rather common, such as "abstinence". "interruption of the act" and "rhythm". Knowledge of these three terms seems to explain the correlation with education suggesting this variable is less a measure of sexual education than of vocabulary and conceptualization skills.

IFor the self-rated efficacy scale the mother was asked to rate herself compared to two other female relatives she was acquainted with, on a series of items typical of theses women's lives: making a baby laugh, talking to strangers, calming an upset child. The score was the number of times she rated herself as the best of the three on that item.

§Our birth weight data relied on maternal recall. There were many babies born an even seven or eight pounds. The questionable accuracy of this data most likely explains its insignificant relationship to the children's nutritional status. The lack of association of birth order and nutritional status may be due to the relatively small family sizes (only $22 \%$ of the children were the fourth or later child).
Table 2. Maternal employment variables

\begin{tabular}{|c|c|c|}
\hline & $n$ & Percent ${ }^{a}$ \\
\hline Mothers working for money & 45 & 56 \\
\hline \multicolumn{3}{|l|}{ Maternal occupations: } \\
\hline Street vending & 16 & 36 \\
\hline Commercial/semiskilled & 13 & 29 \\
\hline Unknown/informal & 6 & 13 \\
\hline Fixed market vending & 4 & 9 \\
\hline Domestic service & 4 & 9 \\
\hline Technical/professional & 2 & 5 \\
\hline \multicolumn{3}{|l|}{ Location where mother works: } \\
\hline Home & 9 & 20 \\
\hline Away from home & 30 & 67 \\
\hline Home and away & 6 & 13 \\
\hline \multicolumn{3}{|l|}{$\begin{array}{l}\text { Number of days mother } \\
\text { works per week: }\end{array}$} \\
\hline $1-3$ days & 11 & 24 \\
\hline $4-6$ days & 18 & 40 \\
\hline 7 days & 16 & 36 \\
\hline \multicolumn{3}{|l|}{$\begin{array}{l}\text { Hours per day mother works } \\
\text { for money: }\end{array}$} \\
\hline $1-3$ hours & 14 & 31 \\
\hline $4-8$ hours & 25 & 56 \\
\hline $9+$ & 6 & 13 \\
\hline \multicolumn{3}{|l|}{ Child care arrangement: } \\
\hline At home with working mother & 12 & 26 \\
\hline Brings with mother to work & 8 & 18 \\
\hline Leaves with adult caregiver & 22 & 49 \\
\hline Leaves with child under 13 & 3 & 7 \\
\hline
\end{tabular}

Percent total sample is shown for "mothers working for money": for all of the other categories, percent of working mothers is shown.

Maternal differentiation, a concept adopted from the sociological term for a level of complexity and organization (Young, 1983), was developed to reflect maternal ability to process a wide variety of information. Maternal differentiation was expected to be positively related to nutritional status through improved decision making and use of resources. Education is usually seen as the strongest indicator of maternal abilities (Cochrane et al., 1982; Ware, 1984) although it is also highly associated with socioeconomic status. Principal component analysis was used to identify a single factor from a variety of maternal characteristics including years of school passed, age, age at first birth, ever having had anemia, stress symptoms, ${ }^{*}$ knowledge and use of various birth control methods, $\uparrow$ self-rated efficacy, $\neq$ the mother's religious activity, and a history of child mortality. Two variables, years of education and a scale measuring knowledge of birth control, loaded on the first factor, which was used here.

Several child characteristics were included as control variables, since they typically covary with nutritional status. These were gender of the child, which was strongly associated with $\mathrm{HA}$ and WA, with girls having lower means, and age of the child, which in this limited range was not associated with nutritional status, but was included in the analyses to control for age bias in some caring behaviors. Birth order and birth weight were found to be unrelated to nutritional status in this sample and are not included in the analyses. $\S$ 
Table 3. Association of child, family, and household variables by maternal work status: $t$-tests and chi-squared values

\begin{tabular}{lccc}
\hline & Not-employed $N=35$ & Employed $N=45$ & $t$ or $\chi^{2}$ \\
Child's anthropometric status & $-1.34(0.96)$ & $-1.61(1.1)$ & 1.16 \\
HA & $-1.37(0.87)$ & $-1.27(1.1)$ & 0.48 \\
WA & $-0.71(0.87)$ & $-0.34(0.87)$ & $1.94 *$ \\
WH & $11.8(5.4)$ & $10.0(5.1)$ & 1.53 \\
Household wealth score & $5.5(3.1)$ & $4.5(3.7)$ & 1.19 \\
Mother's years of school & $0.14(0.95)$ & $-0.11(1.1)$ & 1.12 \\
Maternal differentiation score & $24.8(5.6)$ & $28.5(7.5)$ & $2.38^{*}$ \\
Mother's age in years & $19.8(4.0)$ & $20.6(4.4)$ & 0.76 \\
Mother's age at first birth & $69 \%$ & $60 \%$ & 1.91 \\
Live in extended family & & & \\
Paternal support & $26 \%$ & $73 \%$ & $5.82 *$ \\
None & $36 \%$ & $64 \%$ & \\
Partial & $56 \%$ & $44 \%$ & \\
Full & & & \\
\hline
\end{tabular}

$* P<0.05, * * P<0.01$

Note: The statistic for live in extended family and paternal support is a $\chi^{2}$; the others are all $t$-tests

\section{RESULTS}

\section{The care/support niche and anthropometric status}

Characteristics of maternal employment and child care: the care/support niche. As shown in Table 2, more than half of the mothers $(56 \%)$ worked for income. The most common occupation was street vending (36\% of working mothers). A few were domestic employees, semiskilled workers, or had a fixed vending establishment. Only two had professional or technical jobs. Of those employed, most worked between 4 and 8 hours a day.

There was no difference in level of education, household wealth, or likelihood of living in an extended family between women who worked for earnings and those who did not. Working mothers were significantly less likely to have financial support from the child's father than non-workers. However, almost half the mothers who worked responded that the father provided full support.
Initially it was assumed that the only inadequate care was leaving the child with a young caregiver, as found by Engle (1991). However, after discussions with the testers and members of the community, and given the age of the child, we also included taking children along as inadequate care. Most of the eight children whose mothers took them along were street vendors; who must move frequently or sell at street corners. Given the type of work, and the age of the children (12-18 months), mothers who took their children along probably did not have the time or space to provide adequate care.

The characteristics of the children differed between the adequate and inadequate child care group (Table 3 ). Only $32 \%$ of the children in adequate child care were girls, whereas $82 \%$ of the children in inadequate child care were girls, although there were no differences by employment status.

Table 4. Relationships of family characteristics with child care strategy $(n=80)$

\begin{tabular}{|c|c|c|c|c|}
\hline$n$ & $\begin{array}{l}\text { Non-working mother } \\
35\end{array}$ & $\begin{array}{c}\text { Good child care } \\
34\end{array}$ & $\begin{array}{c}\text { Poor child care } \\
11\end{array}$ & $x^{2}$ \\
\hline \multicolumn{5}{|l|}{ Father provides" } \\
\hline Nothing & $17 \%$ & $35 \%$ & $46 \%$ & 7.16 \\
\hline Partial & $14 \%$ & $18 \%$ & $27 \%$ & \\
\hline All & $69 \%$ & $47 \%$ & $27 \%$ & \\
\hline Extended family & $69 \%$ & $62 \%$ & $27 \%$ & $6.02 * *$ \\
\hline Grandmother helps & $40 \%$ & $38 \%$ & $9 \%$ & 3.78 \\
\hline Percent male children & $43 \%$ & $68 \%$ & $18 \%$ & $9.40^{* * *}$ \\
\hline & $\mathrm{M}(\mathrm{SD})$ & $\mathrm{M}(\mathrm{SD})$ & $\mathrm{M}(\mathrm{SD})$ & $F$ \\
\hline Age of child & 15.2 & 15.9 & 14.1 & $4.37^{* *}$ \\
\hline & $(1.7)$ & $(2.0)$ & $(1.3)$ & \\
\hline Household wealth & $\begin{array}{l}11.8 \\
(5.4)\end{array}$ & $\begin{array}{l}11.2 \\
(5.1)\end{array}$ & $\begin{array}{c}6.3 \\
(3.1)\end{array}$ & $5.33^{* * *}$ \\
\hline Birth order & $\begin{array}{c}2.5 \\
(1.6)\end{array}$ & $\begin{array}{c}2.9 \\
(1.8)\end{array}$ & $\begin{array}{c}3.8 \\
(1.9)\end{array}$ & 2.06 \\
\hline Age of mother & $\begin{array}{l}24.8 \\
(5.6)\end{array}$ & $\begin{array}{l}28.3 \\
(8.6)\end{array}$ & $\begin{array}{l}29.0 \\
(1.7)\end{array}$ & 2.83 \\
\hline Mother's schooling (yrs) & $\begin{array}{c}5.5 \\
(3.1)\end{array}$ & $\begin{array}{c}4.8 \\
(3.9)\end{array}$ & $\begin{array}{l}3.8 \\
(2.9)\end{array}$ & 1.02 \\
\hline Father's schooling (yrs) & $\begin{array}{c}7.3 \\
(2.7)\end{array}$ & $\begin{array}{c}5.6 \\
(3.9)\end{array}$ & $\begin{array}{c}3.3 \\
(3.5)\end{array}$ & 4.72 \\
\hline
\end{tabular}

${ }^{*} P<0.10,{ }^{* *} P<0.05,{ }^{* * *} P<0.01$.

${ }^{a}$ Sample size for father's schooling is 57 .

Note: Post hoc comparisons using Student-Neuman-Kuels test had results as follows: age of child: good child care higher than poor child care; household wealth: non-working and good child care higher than poor child care; age of mother: good child care higher than non-working mother; and father's schooling: non-working mother higher than poor child care. 
Table 5. Associations of care/support niche and control variables with nutritional status indicators

\begin{tabular}{|c|c|c|c|c|c|}
\hline & $n$ & & HA & WA & WH \\
\hline \multicolumn{6}{|c|}{ Control variables } \\
\hline Household wealth & 80 & $r$ & 0.19 & $0.31 * * *$ & $0.26^{* * *}$ \\
\hline Maternal & 79 & $r$ & $0.29 * * *$ & $0.21^{* *}$ & 0.04 \\
\hline \multicolumn{6}{|l|}{ Differentiation score } \\
\hline \multicolumn{6}{|l|}{ Gender of child } \\
\hline Male & 40 & & $-1.26(1.0)$ & $-1.14(1.1)$ & $-0.47(0.90)$ \\
\hline \multirow[t]{2}{*}{ Female } & 40 & & $-1.73(1.1)$ & $-1.49(0.92)$ & $-0.54(0.87)$ \\
\hline & & $t$ & $2.02^{* *}$ & $1.68^{*}$ & 1.08 \\
\hline Age of child & 80 & $\stackrel{r}{C a r}$ & $\begin{array}{r}0.04 \\
\text { iables }\end{array}$ & 0.06 & 0.03 \\
\hline \multicolumn{6}{|l|}{ Family type } \\
\hline Extended & 48 & & $-1.47(1.1)$ & $-1.20(1.1)$ & $-0.36(0.8)$ \\
\hline Nuclear & 32 & $t$ & $\begin{array}{c}-1.54(1.1) \\
0.30\end{array}$ & $\begin{array}{c}-1.49(0.8) \\
1.33\end{array}$ & $\begin{array}{c}-0.72(0.7) \\
1.93^{* *}\end{array}$ \\
\hline \multicolumn{6}{|l|}{ Father provides } \\
\hline No & 23 & & $-1.88(1.2)$ & $-1.56(1.1)$ & $-0.48(1.1)$ \\
\hline Yes & 57 & & $-1.34(0.98)$ & $-1.22(0.89)$ & $-0.51(0.80)$ \\
\hline \multicolumn{6}{|l|}{ Child care strategy ${ }^{a}$} \\
\hline Non-employed & 35 & & $-1.34(0.97)$ & $-1.38(0.88)$ & $-0.72(0.86)$ \\
\hline Good care & 34 & & $-1.38(0.88)$ & $-1.05(1.1)$ & $-0.28(0.95)$ \\
\hline Poor care & 11 & & $-2.34(0.95)$ & $-1.95(0.76)$ & $-0.52(0.53)$ \\
\hline & & $F$ & $4.42^{* * * * a}$ & $3.96^{* * * a}$ & 2.20 \\
\hline
\end{tabular}

$* P<0.10, * * P<0.05,{ }^{* * *} P<0.01$

$t=$ Student's $t$-statistic; $r=$ Pearson's correlation coefficient: $\chi=$ Pearson's chi-squared statistic.

"Post hoc comparisons using Student-Neuman-Kuells procedure indicated the poor child care group to be both shorter and lighter than the others.

Children in poor child care were significantly younger than in the good child care group. They also lived in poorer households, their fathers had less education, and they were less likely to live with extended families.

Associations between maternal work for earnings and child anthropometric status. The nutritional status of children whose mothers were working for earnings was compared to those of non-working mothers using $t$-tests. As Table 4 shows, children of working mothers had significantly higher WH than those of non-working mothers. This result was found even controlling for the confounding variables of maternal differentiation, household wealth, and child gender $\left(F_{\text {work }}=5.98, P=0.017\right)$. Inspection of the values found no outliers; the effect was seen for most of the children.

Associations of care/support niche and child anthropometric status. Father's financial support was associated with higher HA, but not significantly higher WA or WH. Children in extended family households had higher WH than did children in nuclear household units. Extended family households had higher wealth than the nuclear households and fewer young children per adult. Extended family households were also more likely to have a grandmother serving as regular caregiver than were nuclear family households $\left[\chi^{2}(1)=10.28\right.$, $P<0.01)]$. On average, only $35 \%$ of the households had grandmother support in child care.

Child care adequacy (adequate, poor, or nonworking mother) was associated with significant

*Father education was not controlled for because there was too much missing data for the variable $(n=23)$. differences for HA and WA in a one-way analysis of variance (Table 5). Post hoc comparisons using the Student-Neuman-Kuells procedure indicated that for both HA and WA, children in the poor care group were shorter and lighter than those in the adequate alternate care group. The children in the poor care group were shorter, but not lighter, than children with non-working mothers. However, when family wealth, child age and gender, and extended family status* were controlled for in an analysis of covariance, only the lower HA of the poor child care group continued to be significant $[F(2,73)=2.95, P<0.05)]$; WA did not differ by child care adequacy. However, WH was significantly lower in the non-working group than both of the care groups $[F(2,73)=3.53, P<0.03)]$.

Whether there was an association of maternal employment and children's nutritional status independent of child care quality was analyzed with a multiple linear regression. Variables entered into

Table 6. Slopes ( $b$ values) for regression of maternal employment and control variables on nutritional status indicator

\begin{tabular}{llll}
\hline & HA & WA & WH \\
$F$ (Model) & $8.93^{* *}$ & $8.38^{* *}$ & $6.13^{* *}$ \\
$r^{2}$ & 0.09 & 0.09 & 0.12 \\
Mother works $(0,1)$ & & $0.92^{* *}$ & \\
Adequate child care & & \\
$(0,1)$ & & \\
Father support $(0,1)$ & & \\
Extended family $(0,1)$ & & \\
Maternal differentiation & $0.27^{* *}$ & \\
Household wealth & $0.06^{* *}$ & $0.05^{* *}$ \\
Child's gender & & \\
Child's age & & \\
\hline *P<0.05, **P< 0.01. & & \\
Note: Non-significant slopes are shown as dashes.
\end{tabular}


Table 7. Differences in nutritional status of children associated with caregiving behaviors ( $t$-tests and correlations)

\begin{tabular}{|c|c|c|c|c|}
\hline & $n$ & $\begin{array}{c}\mathrm{HA} \\
\mathrm{M}(\mathrm{SD})\end{array}$ & $\begin{array}{c}\text { WA } \\
\text { M(SD) }\end{array}$ & $\begin{array}{c}\text { WH } \\
\text { M(SD) }\end{array}$ \\
\hline \multicolumn{5}{|c|}{ Caregiver washed hands } \\
\hline Never & 53 & $-1.53(1.1)$ & $-1.38(1.1)$ & $-0.56(0.93)$ \\
\hline \multirow[t]{3}{*}{ Ever } & 27 & $-1.42(1.0)$ & $-1.20(0.83)$ & $-0.39(0.79)$ \\
\hline & $t$ & 0.44 & 0.78 & 0.82 \\
\hline \multirow{2}{*}{\multicolumn{2}{|c|}{ Child's hands washed }} & & & \\
\hline & 62 & $-1.48(1.1)$ & $-1.37(1.0)$ & $-0.59(0.93)$ \\
\hline \multirow[t]{3}{*}{ Ever } & 27 & $-1.56(1.1)$ & $-1.14(0.76)$ & $-0.20(0.62)$ \\
\hline & $t$ & 0.79 & 0.38 & $2.07 * *$ \\
\hline \multirow{2}{*}{\multicolumn{2}{|c|}{$-189(0.92)$}} & & & \\
\hline & 20 & $-1.89(0.92)$ & $-1.66(0.81)$ & $-0.59(0.67)$ \\
\hline \multirow[t]{3}{*}{ Complete } & 56 & $-1.31(1.1)$ & $-1.12(0.98)$ & $-0.47(0.92)$ \\
\hline & $t$ & $2.14^{* *}$ & $2.06^{* *}$ & 0.54 \\
\hline \multirow{2}{*}{\multicolumn{3}{|c|}{$\begin{array}{r}\text { Still breastfeeding } \\
-1.53(1.17)\end{array}$}} & & \\
\hline & & & $-1.32(1.06)$ & $-0.46(0.82)$ \\
\hline \multirow[t]{2}{*}{ Yes } & 38 & $-1.45(0.93)$ & $-1.32(0.89)$ & $-0.55(0.96)$ \\
\hline & $t$ & -0.34 & 0.01 & 0.38 \\
\hline Number of eating events & & 0.19 & $0.27 * *$ & 0.20 \\
\hline Active feeding scale & & 0.14 & 0.09 & -0.06 \\
\hline Animal food frequency & & 0.17 & $0.36 * * *$ & $0.35^{* * *}$ \\
\hline Food variety & & 0.14 & 0.15 & 0.07 \\
\hline Percent physical care & & 0.04 & 0.14 & 0.17 \\
\hline Percent emotional care & & -0.11 & -0.04 & 0.06 \\
\hline
\end{tabular}

${ }^{*} P<0.10, * * P<0.05, * * * P<0.01$.

Note: Statistics for continuous measures are Pearson's $r$.

the procedure were the dichotomous measures of maternal employment, adequate child care (with non-working mother considered adequate), paternal support, an extended family household, child gender, and the continuous measures of maternal differentiation, household wealth, and age of the child in months.

As Table 6 shows, the children of working mothers still had higher WH scores than those of the non-working mothers, even controlling for all of the other variables. For HA, the adequacy of the child care (either non-working mother or adequate child care) was significant, but maternal employment was not. Paternal support was no longer significant. These findings underscore the importance of the care/support niche for understanding effects of maternal work on children.

* Because the observers were instructed to remain in the home until the child had eaten lunch, the amount of time per household on the two separate days varied from family to family. Therefore, the total number of eating events observed could be higher if the observation time were longer. A longer observation time often occurred if the lunch were later. In order to determine whether these associations would continue to appear when the rate of eating events was used, rather than the total amount, a ratio of feeding episodes/hours of observation was calculated. Number of feeding events was not significantly associated with nutritional status. However, this correction may remove important variance in the number of eating episodes, since a mother who served a later lunch, but more snacks prior to that event appears to have a better nourished child. Further, number of servings of protein was associated with number of eating events $(r=0.48, P<0.01)$. Therefore, it was decided to continue to use the uncorrected measure in the analyses.
Measures of caregiving, nutritional status and maternal employment

In order to examine whether observed caregiving behaviors could account for the association of maternal employment with WH, or child care adequacy with $\mathrm{HA}$, the associations of the 10 caregiving measures with nutritional status, work for earnings and adequacy of child care were examined. These caregiving behaviors were in the areas of hygiene (two), psychosocial care (two), food and feeding behaviors (five), and health care utilization (one).

Table 7 presents the associations of these caring behaviors with child nutritional status. Among the hygiene behaviors, whether the caregiver ever washed her hands was unrelated to the child's anthropometric status, but children whose hands were washed had significantly higher WH than children whose hands were never washed. Percent of time the caregiver was observed in emotional and physical care was unrelated to the child's nutritional status. Among the food and feeding variables, significant associations were seen for amount of animal food in the diet (WA and WH) and the total number of feeding episodes observed over the two days (significant for WA, and marginally with HA and WH).* Food variety, mother's active feeding behavior, and current breastfeeding status were unrelated to child nutritional status. Children who had been properly vaccinated had more adequate HA and WA measures. Of the 10 measures, four were associated with child anthropometric status.

Only one of the 10 caring behaviors differed by mother's work status: frequency with which the caregiver washed her hands $\left[\chi^{2}(1)=3.98\right.$, $P<0.01)]$. Working mothers were less likely to ever wash their hands $(24 \%)$ than non-working 
Table 8. Relationships of caring behaviors with child care strategy

\begin{tabular}{|c|c|c|c|c|}
\hline & $\begin{array}{c}\text { Non-working mother } \\
35\end{array}$ & $\begin{array}{c}\text { Good child care } \\
34\end{array}$ & $\begin{array}{c}\text { Poor child care } \\
11\end{array}$ & $\chi^{2}$ \\
\hline Caregiver ever washed hands & $43 \%$ & $26 \%$ & $9 \%$ & 5.07 \\
\hline Child's hands ever washed & $46 \%$ & $26 \%$ & $18 \%$ & 4.24 \\
\hline Vaccination complete & $79 \%$ & $78 \%$ & $40 \%$ & $6.75^{* *}$ \\
\hline \multirow[t]{2}{*}{ Still breastfeeding } & $43 \%$ & $56 \%$ & $36 \%$ & 1.80 \\
\hline & $\mathrm{M}(\mathrm{SD})$ & $\mathrm{M}(\mathrm{SD})$ & $\mathrm{M}(\mathrm{SD})$ & $F$ \\
\hline Number of eating events & $4.9(1.7)$ & $4.4(1.7)$ & $3.8(1.0)$ & 2.24 \\
\hline Active feeding scale & $1.05(0.76)$ & $1.13(0.82)$ & $.59(0.62)$ & 2.06 \\
\hline Animal food frequency & $1.22(0.89)$ & $1.28(0.85)$ & $1.13(0.73)$ & 0.15 \\
\hline Food variety & $4.06(1.7)$ & $3.57(1.0)$ & $2.91(0.9)$ & $3.33^{* *}$ \\
\hline Percent physical care & $21.0(12.2)$ & $27.2(15.0)$ & $22.9(17.2)$ & 1.71 \\
\hline Percent emotional care & $30.1(16.9)$ & $23.8(17.3)$ & $35.9(23.3)$ & 2.21 \\
\hline
\end{tabular}

$* P<0.10, * * P<0.05, * * * P<0.01$

Note: For food variety, with Student-Neuman-Kuels test, the poor child care group is lower than the other two groups.

mothers $(46 \%)$. On the other hand, working mothers were marginally more likely to provide physical care $(26 \%$ of the time) than were nonworkers $(20.9 \%)[t(78)=1.68, P<0.10)]$. There was no difference in the percent still breastfeeding; $43 \%$ of non-working women, compared to $51 \%$ of working women were still breastfeeding.

Caring behaviors were also compared for the three child care groups: mother not working, adequate child care, and inadequate child care. As Table 8 shows, three variables differed by the child care adequacy: food variety (poor child care less than the other two), likelihood of having completed vaccinations (less frequent in the poor care group), and caregiver ever washing her hands (marginally lowest in the poor care group). Current breastfeeding did not differ by adequacy of child care.

More caregiving measures were associated with child anthropometric status [child hands washed (WH), protein and number of meals given (WA and WH), and complete vaccinations (HA and WA)] than they were with maternal work for earning. Only one measure was significantly associated with maternal work (less handwashing by working mothers), and there was marginally more physical care among working mothers. Three measures were associated with child care adequacy. Caregivers relying on inadequate care were less likely to wash their own hands, provided a smaller variety of foods and were less likely to have complete vaccination records. As noted previously, almost all of the observations were of the mother $(98 \%)$.

\section{CONCLUSIONS}

This study was designed to compare the relative effects of maternal work for earnings and child care adequacy on children's anthropometric status in a low income area of Managua, and to examine whether there were differences in the way mothers performed 10 caregiving behaviors as a function of their work status or method of child care.

In this sample, over half of the mothers of the 12-18-month-old children had worked for income in the previous week, usually away from home and for at least four days of the week. Support from the child's father was relatively limited, with over a quarter of the women single, and only half of the fathers providing sufficient support for the child's upkeep. Working women were older than nonworkers, and had significantly less support from the child's father, but did not differ in education, maternal differentiation score, household wealth, or whether they lived in an extended family.

Child care strategies of working mothers were divided into those considered adequate, which was care at home either with the mother while she worked or with a caregiver who was at least a teenager $(>12)$, and inadequate care was considered to be care by another child or being taken with the mother to the place of work. The latter was considered to be inadequate care since the majority of those taking children along were street vendors, considered an inadequate environment for a toddler. Women who used poor child care were poorer and less likely to live in extended households, were older than the non-workers, but apparently did not yet have teenaged children who could watch their young children, and had less educated partners, although they themselves did not differ in educational attainment. Children left with poor care were significantly younger than those in good care, and significantly more likely to be girls.

The findings support the hypothesis that there is a positive association of women working for earnings with weight for height in this child age group, either alone or controlling for other socioeconomic variables. Other studies have also reported positive associations of child anthropometric status with women's work for earnings, particularly weight for height in Mali (De Groote et al., 1994), Niger (Brown et al., 1994); the Philippines (Blau et al., 1996), and in Guatemala (Engle and Pedersen, 1989; Engle, 1991, 1993, 1995). The association of work with weight for height, a shorter-term measure of anthropometric status, might suggest that during the critical weaning period, the woman's income could be used for higher quality 
weaning foods, resulting in the more transient increase in weight (short and chubby), particularly for children who had been stunted. In Panama, Tucker found children whose mothers worked consumed more kilocalories and protein, were less likely to be infected with parasites, and had higher hemoglobin status (Tucker, 1989; Tucker and Sanjur, 1988). Unfortunately, we do not have expenditure data nor quantitative measures of income in this study because of extremely high rates of inflation and economic instability at the time. However, these data are consistent with the hypothesis that women's economic contribution, particularly when the economy is in crisis and there is little paternal support, can make a critical difference in their children's growth.

Children who had adequate child care while their mothers were working did not differ in anthropometric status from children who were at home with their non-working mothers, whether or not one controls for confounding variables of wealth, extended family membership, child age or gender. When these variables were controlled for, both children with good and poor care had better WH scores than those with non-working mothers. However, those with inadequate child care had lower HA than those who had adequate care, even controlling for confounds. Provision of child care by young children has been shown to be associated with poor growth outcome and poverty in other studies. In Guatemala, women who brought their children with them when working were poorer, tend to work in "informal sector" jobs, and had children of lower nutritional status than women who had an adult caregiver (Engle, 1991). These may be the children at greatest risk of poor growth. However, there may be some cognitive advantages of increased time with the mother from being "taken along". The Nigerian Positive Deviance Study (Aina et al., 1993) of low income mothers and twoyear-olds in Lagos state found that children who stayed close to their working mothers scored higher in mental development (as measured by the Bayley Scales (Bayley, 1969) but were more malnourished, while those left at home in good care scored lower but were better nourished.

Multiple regression equations were constructed to evaluate the independent effects of maternal work for earnings and adequacy of child care on child anthropometric status, controlling for possible confounding variables. The results suggested that for HA, inadequate child care was associated with longer-term stunting, but maternal employment was unrelated. For WA, only wealth was a predictor. Maternal employment was a more important asset than was poor child care a detriment to children's weight for height. These two nutritional status measures were not significantly associated; the children with working mothers were not more stunted than those with non-working mothers.
A similar analysis was performed for a slightly older group of children in Guatemala (8-35 months of age) (Engle, 1991). As in the Nicaraguan sample, children with good quality child care were as well nourished as children of non-working mother but children with inadequate care (cared for by preteen caregivers) were more malnourished than children with adequate care. Quality of child care was a more important predictor of child nutritional status than maternal work. In the Guatemalan sample, the net effect of inadequate care on child anthropometric status was seen in WH, rather than HA. The Guatemalan context is quite different, with a much higher percent of women receiving full support from their partners, and less maternal employment. The positive effect of maternal employment on WH was not found in Guatemala.

In order to examine possible differences in caregiving as a function of maternal employment or child care adequacy, observations of child/caregiver interactions on two separate days were made, and 10 care behaviors were defined. It must be noted that almost no observations were made of alternate caregivers' behavior, as the observations nearly always took place while the mother was at home. Therefore, we are observing only the possible spillover effect of working mothers' greater workloads or less free time on their behavior with their children when at home.

The only caregiving variable to distinguish between working and non-working mothers was whether they ever washed their hands, with working mothers washing less. Also, three variables distinguished the mothers who provided adequate care from the inadequate care group: they provided a larger variety of foods, were more likely to have completed the measles vaccinations, and were slightly less likely to ever wash their hands. It was presumed that the association with vaccination and personal cleanliness represented a measure of the mother's caring attentiveness to preventive health care and hygiene, not a biological effect on growth status. Thus the families in which inadequate care occurred demonstrated some poorer caring behaviors, even with the mother present.

Child anthropometric status was associated with some caring behaviors. Children whose hands were washed more often had better weight for height, those receiving more animal protein had higher WA and WH, those with more meals given had better WA, and finally, those with completed vaccinations had improved HA and WA.

The relative insignificance of the father's support for children could be due to several factors: the crudeness of the measure used, and the high degree of instability in these families. Considering the age of the children, the fact that $26 \%$ of the fathers provided no support, and that the father is the household head in only half of the families, suggests relatively low reliance on the man's income, a situ- 
ation which contrasts with other areas in Latin America (Engle, 1995).

The significant sex differences in attained height were not surprising; as in many areas, boys were significantly taller than girls at this age, although the difference disappeared when controlling for socioeconomic variables. However, the significant association between inadequate child care and gender had not been anticipated. Girls were much more likely to be cared for with inadequate child care than were boys. Many studies have not found strong gender preference in Latin American societies (Engle et al., 1983), but there may be differences in the kinds of protection that parents think boys and girls need; in Guatemala, Engle (1989) found that parents were much less likely to believe that one could leave girls with an alternate caregiver than boys. Thus, the mothers may have taken girls along to provide more protection, possibly to the detriment of the child's growth. The results reported here should be considered tentative as the sample size in the group was very small; more research is needed to determine whether this finding is replicated elsewhere, and to identify parental beliefs about boys and girls' needs for child care.

The lack of association of continued breastfeeding in this group with child anthropometric status, maternal employment, or quality of child care is surprising. Certainly there is no evidence of the negative associations of prolonged breastfeeding reported in Peru (Bentley et al., 1992).

Our study clearly shows a group at risk in this population; children of women who lack adequate strategies for alternate child care. These women tend to have work that is incompatible with good child care, such as street vending, and a lack of family opportunities for care. Programs to provide child care for working women should target services toward this group of poor families; they are growing in number in most cities of less developed countries today (United Nations, 1995). While we recognize the potential benefits of maternal employment, we must also recognize that children are at risk when their mothers lack the resources to successfully manage both work for earnings and provide adequate child care. Strategies for encouraging or even requiring fathers' support for children should be added to the children's agenda (United Nations, 1995).

Acknowledgements - The authors wish to express their thanks to colleagues at the Universidad National Autonoma de Nicaragua, in particular, Yadira Mendrano and Josefina Bonilla.This research was supported by a grant from the Joint Nutrition Support Group and UNICEF to $M$. Zeitlin, and by a grant from UNICEF to Engle and LaMontagne.

\section{REFERENCES}

Adelman, C. (1983) An analysis of the effect of maternal care and other factors affecting the growth of poor children in Lima, Peru. D.Sc. Thesis, Johns Hopkins University, Baltimore.

Aina, T. A., Agiobu-Kemmer, I., Etta, E. F., Zeitlin, M. F., Setiloane, K. and Armstrong, H. (1993) Early Childhood Care, Development and Nutrition in Lagos State, Nigeria. Phase I survey results from the Positive Deviance in Nutrition Research Project, Tufts University, Medford, MA.

Barry, H. and Paxson, L. (1971) Infancy and early childhood: cross cultural codes. Ethnology 10, 466-508.

Bayley, N. (1969) Manual for the Bayley Scales of Infant Development. Psychological Corporation, New York

Bentley, M. E., Caulfield, L. E., Torun, B., Schroeder, D. Hurtado, E. (1992) Maternal feeding behavior and child appetite during acute diarrheal episodes and subsequent child health in Guatemala. FASEB Journal 6, 1648.

Blau, D. M., Guilkey, D. K. and Popkin, B. M. (1996) Infant health and the labor supply of mothers. Journal of Human Resources 31(1), 90-139.

Blumberg. R. L. (1988) Income under female versus male control: hypothesis from a theory of gender stratification and data from the Third World. Journal of Family Issues 9(1), 51-84.

Brown, L. R., Yohannes, Y. and Webb, P. (1994) Rural labor-intensive public works: impacts of participation on preschooler nutrition. Evidence from Niger. American Journal of Agricultural Economics 76(5), 12131218.

Cochrane, S., Leslie, J. and O'Hara, C. (1982) Parental education and child health: intra-country evidence. Health Policy and Education 2, 213-250.

De Groote, H., Kennedy, E., Payongayong, E. and Haddad, L. (1994) Credit with education for women in Mali: impacts on income, food security, and nutrition. Mimeo, Report to the United States Agency for International Development, International Food Policy Research Institute, Washington, DC.

Engle, P. L. (1989) The social context of child care. Paper presented at Society for Research in Child Development Meetings, Kansas City, MO.

Engle, P. L. (1991) Maternal work and child care strategies: nutritional effects. Child Development 62, 954-965.

Engle, P. L. (1992) Care and Child Nutrition. Report for International Congress on Nutrition, UNICEF, New York.

Engle, P. L. (1993) Influences of mother's and father's income on children's nutritional status in Guatemala. Social Science \& Medicine 37(11), 1303-1312.

Engle, P. L. (1995) Mother's money, father's money, and parental commitment: Guatemala and Nicaragua. In Engendering Wealth and Well Being, eds R. Blumberg, C. A. Rakowski, I. Tinker and M. Monteón, pp. 155180. Westview, Boulder.

Engle, P. L. and Nieves, I. (1993) Intra-household food distribution patterns among Guatemalan families in a supplementary feeding program: behavior patterns. Social Science \& Medicine 36(12), 1605-1612.

Engle, P.L. and Pedersen, M.E. (1989) Maternal work for earnings and children's nutritional status in urban Guatemala. Ecology of Food and Nutrition 22, 211-223.

Engle, P. L. and Zeitlin, M. (1996) Active feeding behavior compensates for low child demand among Nicaraguan one-year-olds. Journal of Nutrition 126(7), 1808-1816.

Engle, P. L., Yarbrough, C. and Klein, R. E. (1983) Sex differences in the effects of nutrition and social environment on mental development in rural Guatemala. In Women's Issues in Third World Poverty, eds M. Buvinic, 
M. A. Lycette and W. P. McGreevey, pp. 198-215. Johns Hopkins University, Baltimore, MD.

Engle, P. L., LaMontagne, J. F. and Zeitlin, M. F. (1992) Caring capacity within the household and nutritional status: an observational study of caring behaviors in Managua, Nicaragua. Final Report prepared for UNICEF, New York.

Engle, P. L., Menon, P. and Haddad, L. (1997) Care and Nutrition: Concepts and Measurement. International Food Policy Research Institute Occasional Paper, Washington, DC (also Working Paper no. 18, Food and Nutrition Division, International Food Policy Research Institute, Washington, DC).

Hoffman, L.W. (1989) Effects of maternal employment in the two-parent family. American Psychologist 44(2), 283-292.

Lavoipierre, G. J., Keller, W., Dixon, H., Dustin, J. P. and Tendam, G. (1983) Measuring Change in Nutritional Status. World Health Organization, Geneva.

Leslie, J. (1988) Women's work and child nutrition in the Third World. World Development 16(11), 1341-1362.

Leslie, J. and Paolisso, M. (eds) (1989) Women, Work and Child Welfare in the Third World. Westview, Boulder.

Martorell, R. (1989) Body size, adaptation, and function. Human Organization 48, 16-20.

Shah, P. M., Walimbe, S. R. and Dhole, V. S. (1979) Wage-earning mothers, mother substitutes and care of young children in rural Maharashtra. Indian Pediatrics $16,167-173$
Super, C. M. and Harkness, S. (1986) The developmental niche: a conceptualization of the interface of child and culture. International Journal of Behavioral Development 9, $545-569$.

Tucker, K. (1989) Maternal employment, differentiation, and child health and nutrition in Panama. In Women, Work and Child Welfare in the Third World, eds $\mathbf{J}$. Leslie and M. Paolisso. Westview, Boulder.

Tucker, K. and Sanjur, D. (1988) Maternal employment and child nutrition in Panama. Social Science \& Medicine 26(6), 605-612.

United Nations (1990) The World's Women 1970-1990: Trends and Statistics. United Nations, New York.

United Nations (1995) The World's Women 1995: Trends and Statistics. United Nations, New York.

Vial, I. and Muchnik, E. (1989) Women's market work, infant feeding and infant nutrition among low income women in Santiago, Chile. In Women, Work and Child Welfare in the Third World, eds $\mathrm{J}$. Leslie and $\mathrm{M}$. Paolisso. Westview, Boulder.

Ware, H. (1984) Effects of maternal education, women's roles and child care on child mortality. In Child Survival: Strategies for Research, eds W. H. Mosely and L. C. Chen, pp. 191-214. The Population Council, New York

Young, F. W. (1983) Interdisciplinary Theories of Rural Development. JAI Press, Greenwich, CT. 